implications of any pressure by doctors that might delay the implementation of a comprehensive free family planning service in this country.-We are, etc.,

\begin{tabular}{|c|c|}
\hline $\begin{array}{l}\text { GEORGE PICKERING } \\
\text { President }\end{array}$ & $\begin{array}{l}\text { JOHN A. LORAINE } \\
\text { Chairman, } \\
\text { Management Committee }\end{array}$ \\
\hline $\begin{array}{l}\text { CAROLINE DEYS } \\
\text { DENYS V. I. FAIRWEATHER } \\
\text { C. M. FLETCHER } \\
\text { PETER J. HUNTINGFORD } \\
\text { J. P. LESTER } \\
\text { GEORGE MORRIS }\end{array}$ & $\begin{array}{l}\text { DAVID E. ROBERTSON } \\
\text { MICHAEL SMITH } \\
\text { TOM STUTTAFORD } \\
\text { TAYLOR } \\
\text { BARBARA TONGE } \\
\text { DAVID P. WINSTANLEY }\end{array}$ \\
\hline
\end{tabular}

Doctors and Overpopulation Group

143 Cranley Gardens,

London N.10

1 Birth Control Campaign, The Benefits of Birth Control-Aberdeen's

\section{Multiplicity of Tests}

SIR,-Drs. A. V. Hoffbrand and A. Lavoie are to be complimented on their paper "Megaloblastic Anaemia" (8 June, p. 550) for its lucidity, conciseness, and comprehensiveness. It illustrates the best in modern medicine, and also the worst.

I would cavil with them on one point: they state that in order to make a diagnosis of megaloblastic anaemia it is necessary to carry out 14 tests and, to distinguish between vitamin $B_{1}$, and folate deficiency, another four. It is the 14 tests that I query. It may be that with some of the patients a diagnosis cannot be established until all these investigations have been completed, but I find it difficult to believe that most patients require more than a very few tests.

It seems to me that the authors are somewhat confused about differences between research and clinical practice. In the former the information collected about each patient is that which is relevant to the research as a whole; in clinical practice the information collected is that which is relevant to the patient.

Much research has been done which demonstrates that in various fields-for example, thyroid disease-the many tests available are unnecessary in a majority of cases since the additional information provided by more than a few tests is very small. This point is ignored in the teaching to medical undergraduates so that the present generation of physicians cheerfully orders innumerable tests which ultimately have no function other than to satisfy idle curiosity or to spend other people's money. The consequence of this is that when medical graduates leave research centres or go into general practice their inability to order innumerable tests makes them feel that they are not practising real medicine and this is one of the factors which leads to the lack of morale in the profession.

I am not suggesting that we should go back to the days of Addison, but I do think that in a definitive paper such as this the need for tests should be given full justification.-I am, etc.,

Department of Psychiatry,

Max Hamilton

University of Leeds

\section{Medical Reconnaissance Service}

SIR,-I refer to the article by Drs. R. J. F. H. Pinsent and J. B. Peacock (13 July, p. 129). If we wish to retain family doctoring the doctors must accept responsibility for pro- viding a 24-hour service to their patients, and while there will always be some unnecessary calls and some people unduly demanding of the service, it may be that better public education is what is required if these are in a majority. I am particularly concerned at the suggestion in this article that a state registered nurse should be used to provide a medical reconnaissance service. Diagnosis is a medical responsibility and the comparison with the hospital situation is invalid since the patients in hospital are already under medical direction for the complaints for which they were admitted and presumably were fully examined on admission.

In the nursing profession we too are suffering a severe manpower shortage. It is becoming increasingly difficult to provide an adequate nursing service and it is very doubtful whether nursing duties should be extended to relieve the doctors of medical duties while we are still unable to meet the nursing needs of our patients in the community. In some places a night visiting nursing service is in operation and there is no doubt that it would be desirable to extend this to many more areas. Patients already under the care of the district nursing sister are referred to the night sisters so that 24 hour nursing surveillance can be given to very ill patients and necessary treatments carried out. When a doctor is required for one of these patients the night sister would normally first be contacted and would call him as in hospital, but we would not expect the night nurse to deal with primary calls I am amazed at the suggestion that a second person could be used as driver/operator. This would seem to me to be a quite un neces ary waste of manpower and money. In planning the health services within the districts it is important for all health needs to be discussed on an interdicciplinary basis. It is depressing that some doctors still see the main nursing contribution to be one of saving doctors' time.-I am, etc.,

M. E. LINDARS Buckinghamshire Area Nearsing Officer Stone,
Aylesbury, Buck

\section{Tests of Hearing in School}

SIR,-Your leading article on this subject (6 July, p. 3) draws attention to the usefulness of impedance audiometry and the known disadvantages of the more traditional sweep testing methods. While I agree that impedance audiometry is a most useful additional means of highlighting or confirming middle and inner ear pathology, I would respectfully point out that it does not screen hearing ability, except where the make of the instrument allows such a monaural screen at one frequency and one intensity level.

Ferrer's paper, ${ }^{1}$ while indicating the percentage of children with abnormal middle ear pressures who pass a sweep hearing test, also indicates that $20 \%$ of children who had failed a sweep hearing test had apparently normal middle ear pressures. Were sweep hearing tests to be carried out as an isolated exercise I would agree that cases of eustachian inoompetence or even possibly serous otitis media might be missed. The clinical signs of both these conditions are well described in the literature and provided the mobility of the tympanic membrane is tested by insuffation most school medical officers at the first medical examination should be able to identify them, whether the employing authority is a local authority, as in the past, or the area health authority, as at present.

I hope that we will not lose sight of the twofold purpose of the sweep hearing test. It firstly identifies children who because of impaired hearing may suffer educationally. It places them in an "educationally at risk" category and such information is very important for both school teacher and medical officer. It also focuses the M.O.'s attention on the health of the external and middle ears and triggers off a series of full audiometric and clinical examinations. Admittedly some $55-58^{\circ}$ of children who pass their sweep test may have abnormal middle ear pressures at the time of testing, but is this as crucial educationally or even prognostically as a proved drop in hearing threshold? The long-term effects of eustachian incompetence (often fluctuating) are relatively unknown; the long-term effects of even a minor fluctuating hearing loss are well documented and most authors agree that "glue ear" is more often than not discovered because of a failed sweep test and subsequent follow-up.

A valid criticism of both sweep testing and impedance testing relates to the time the tests are carried out. These measures represent only a clinical situation at a specific point in time; later tests may produce a different picture. This objection is partly met when a team of doctors, nurses, teachers, and audiometricians trained in the identification of children with hearing impairment rely upon each other's observations to ensure that no hearing-impaired children will be missed. Tho these workers sweep hearing test results are globally more acceptable as an observation than the relatively clinical nature of impedance audiometry.

We are fortunate in having an impedance audiometer in our Exeter children's audiology clinic and I have no doubt about its value and usefulness. I would, however, criticize its use as a screening technique because despite its advantages much more useful and educationally relevant information is produced when hearing is screened.-I am, etc.,

C. P. HALletT Senior Medical Officer (Audiology) Exeter Health Care District, Devon A.H.A.), Exeter

1 Ferrer, H. P., Public Health, 1974, 88, 153.

\section{Diabetic Ketoacidosis Presenting as Neurosurgical Emergencies}

SIR,-We read with interest the papers by Dr. J. M. Anderson and Mr. R. S. Maurice(V) illiams (6 July, pp. 22 and 24). In the first paper Dr. Anderson describes three cases of diabetic ketoacidosis presenting with focal neurological signs mimicking neurosurgical conditions. We have recently reported ${ }^{1}$ six cases of fatal diabetic ketoacidotic coma in which there was conclusive histological evidence of focal ischaemic lesions due to small-vessel occlusion by fibrin which in our opinion accounted for the abnormal neurological state of the patients. We believe that the symptoms in all three cases described by Dr. Anderson can be explained on this 